\title{
O LEGADO DA DITADURA PARA A EDUCAÇÃO BRASILEIRA
}

\author{
LUIZ ANTÔNIO CUNHA*
}

\begin{abstract}
RESUMO: Dois são os vetores do legado da ditadura: a simbiose Estado-capital e a regeneração moral do indivíduo e da sociedade. O primeiro consistiu em programas de bolsas de estudos para alunos de baixa renda nas escolas privadas de ensino básico. E prossegue no ensino superior por meio do Programa Universidade para Todos, desde 2005. Outro vetor consiste na atribuição à educação, principalmente à educação pública, de instrumento para regenerar indivíduos e a própria sociedade, que teriam perdido os valores básicos da sociabilidade, especialmente os valores morais do cristianismo. Essa ideologia teve na Escola Superior de Guerra a fonte da Educação Moral e Cívica. Vários projetos de lei pretendem sua retomada em padrões similares.
\end{abstract}

Palavras-chave: Ditadura e educação. Público e privado. Educação e moral.

\section{THE LEGACY OF DICTATORSHIP FOR BRAZILIAN EDUCATION}

ABSTRACT: Two vectors are the legacy of dictatorship in Brazil: education treated according to the State-capital symbiosis and education treated as an instrument of moral regeneration of the individual and society. State support to capital in the educational field consisted of scholarship programs for lowincome students in private primary schools. It has followed the same path in higher education via the Programa Universidade para Todos (University for all Programme), since 2005. Another vector consists in ascribing to education, particularly public education, the means for regenerating individuals and society itself, which have lost the basic values of sociability, especially the moral values of Christianity. This ideology has had on the Escola Superior de Guerra (War College) the source of Moral and Civic Education. Several law proposals intend to resume similar patterns.

Key words: Dictatorship and education. Public and private education. Education and morality.

Faculdade de Educação da Universidade Federal do Rio de Janeiro (UFRJ). Rio de Janeiro (RJ) Brasil.

Contato com o autor: <lacunha@globo.com> 


\section{L'HÉRITAGE DE LA DICTATURE POUR L'ENSEIGNEMENT BRÉSILIEN}

RÉSUMÉ: Il y a deux vecteurs de l'héritage de la dictature : la symbiose Étatcapital et la régénération morale de l'individu et de la société. Ce premier est consistitué de programmes de bourses pour des élèves en difficulté financière dans des écoles privées d'enseignement de base. Et cela continue dans l'enseignement supérieur par le Programa Universidade para Todos, depuis 2005. L'autre vecteur consiste à attribuer à l'éducation, surtout à l'enseignement public, un rôle d'instrument pour régénérer les individus et la société elle-même, ceux qui auraient perdu les valeurs basiques de sociabilité, spécialement les valeurs morales du Christianisme. Cette idéologie a eu à l'École Supérieure de Guerre la base de l'Éducation Morale et Civique. Plusieurs projets de loi en veulent la reprise sous des normes semblables.

Mots-clés: Dictature et éducation. Public et privé. Éducation et morale.

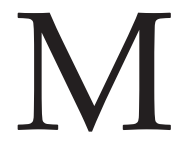

uita coisa já foi escrita e ainda se escreverá sobre a educação no tempo da ditadura. Este artigo não se propõe a acrescentar dados ou análises sobre a bibliografia existente, tampouco a contestá-la. A proposta é, ao contrário, tratar do que foi legado pela ditadura à educação brasileira em sua configuração atual. Apesar do muito que foi desfeito, a duras penas, desde 1985, o que persiste, em linhas gerais? É a resposta a essa pergunta que motivou este artigo.

Ao invés de partir de uma análise abrangente do que foi a ditadura iniciada em 1964, o que não caberia aqui, começo com algumas proposições sobre ela, indispensáveis para a compreensão do tema que será tratado neste artigo.

(i) A ditadura não foi qualificada aqui de militar. Essa adjetivação foi empregada durante a luta, e foi útil para unificar amplos e até contraditórios setores sociais e políticos, de modo a isolar os detentores mais visíveis da Presidência da República e o aparato jurídico-político outorgado pelo "Comando Supremo da Revolução". No entanto, essa qualificação não dá a devida importância à mobilização de massa civil empreendida antes e imediatamente após a deposição do presidente João Goulart, nem à participação do Congresso Nacional nessa deposição, antes mesmo que as forças militares tivessem assumido o controle ostensivo do espaço público e iniciado a repressão político-ideológica contra a "subversão". A deposição do presidente Goulart pelo Congresso, quando ele ainda estava no território nacional, facilitou sobremaneira a adesão de unidades militares aos golpistas, particularmente dos oficiais que se pautavam pela legalidade, independentemente de posição contrária às reformas de base. Os golpistas civis foram, então, condição de possibilidade para o sucesso do golpe militar. ${ }^{1}$ A existência de um mundo civil, oposto em tudo ao mundo militar, faz parte de uma ideologia formada e difundida nas academias militares, nos quartéis 
e nas bases navais e aéreas. ${ }^{2}$ Sociologicamente, o que se opõe ao campo militar não é o campo civil, mas o campo político, o campo econômico, o campo educacional, o campo esportivo, entre outros (BOURDIEU, 1974).

(ii) Os militares brasileiros não eram privatistas. Ao contrário, sua disposição espontânea era estatista, o que ficou claro na economia. Apesar das preferências de vários dos ministros da Fazenda e do Planejamento, foram criadas, no período ditatorial, mais empresas estatais do que até então. $\mathrm{O}$ mesmo pode ser dito para a educação. Grande parte da oficialidade tinha passado por escolas públicas, na educação básica, inclusive os colégios militares e os preparatórios do Exército e da Aeronáutica, bem como o Colégio Naval - que eram tidas por eles em alta conta, particularmente pela qualidade do ensino nelas ministrado.

(iii) Não é adequado chamar de militares as políticas educacionais formuladas e implementadas durante a ditadura. A não ser em um caso, que será tratado mais adiante, o da Educação Moral e Cívica, os militares não tinham propriamente projetos para a área de educação. Até mesmo quando eles enveredavam pelo setor, assumiam o que seus informantes qualificados opinavam, como o general Meira Mattos no seu famigerado relatório sobre o ensino superior, em 1967 (CUNHA, 2007a, p. 85 ss.). Os militares formularam e executaram políticas para a repressão ideológica e policial para as escolas e universidades públicas, mas mesmo assim, não se deve esquecer o protagonismo de ministros civis da Educação, que vieram a dar nome às normas repressoras do movimento estudantil - a Lei n. 4.464/64 e o Decreto-Lei n. 228/67, respectivamente "Lei Suplicy" e "Decreto Aragão", ambos docentes das maiores universidades do país: a USP e a UFRJ. Será que os golpistas não tinham um projeto para a educação? Mostro que tinham. Pelo menos para o ensino superior, dispunham de projeto elaborado pelo Instituto de Pesquisas e Estudos Sociais (Ipes), o intelectual orgânico coletivo do golpe, a mesma entidade que deu forma ao Estatuto da Terra. Mostro, também, que se não foi logo baixada uma lei para institucionalizar o projeto educacional, é porque ele já se encontrava em grande parte implantado. Cumpria, isto sim, neutralizar (quando não eliminar) os opositores e aumentar a velocidade de implantação do projeto. Reitores foram demitidos, professores foram afastados, bibliotecas foram expurgadas, mas a Lei de Diretrizes e Bases da Educação Nacional (LDBEN) e o Conselho Federal de Educação (CFE), com seus pareceres e resoluções, mais o Plano Nacional de Educação foram mantidos, vindo este último a ser o alvo de algumas modificações. O CFE permaneceu com a maioria de seus conselheiros em atividade, inclusive 
Anísio Teixeira, ainda que destituído do cargo de reitor da Universidade de Brasília nos primeiros dias de abril de 1964, pela ação "revolucionária". Do projeto do Ipes saíram as diretrizes da modernização tecnocrática e da privatização, no duplo aspecto de "integração escola-empresa" e de pagamento do ensino nos estabelecimentos oficiais.

(iv) Não houve uma política educacional da ditadura. O uso do plural é mais adequado, pois várias políticas educacionais segmentadas foram formuladas e implementadas, parte delas contraditórias. Para citar apenas um caso exemplar, a profissionalização universal e compulsória no ensino de 2 o grau, determinado pela Lei n. 5.692/71, era contraditória com o ciclo básico nos cursos superiores de graduação, que tinha, entre seus objetivos, "evitar a precoce opção pela carreira" (CUNHA, 2005, p. 182; CUNHA, 2007 a, p. 228). Assumo que a compreensão do processo de formulação e implementação das políticas educacionais na ditadura deve ser aperfeiçoada mediante o entendimento de que vários grupos de interesse procuraram, com sucesso variado, influenciar o Ministério da Educação, inclusive pelo recurso a alianças na alta oficialidade. Em decorrência deste item e do anterior, o correto é falar de "políticas educacionais na ditadura".

(v) Algumas políticas educacionais na ditadura nada mais foram do que o prolongamento das que vinham sendo implementadas desde o Estado Novo e logo após, como a extinção do exame de admissão e a junção do primário ao ginásio, determinadas pela Lei n. 5.692/71. Pelo menos no Distrito Federal/estado da Guanabara e no estado de São Paulo, esse processo já estava em curso, sob formas distintas. $\mathrm{O}$ mesmo pode ser dito a respeito de vários elementos da reforma universitária, como a substituição do regime de cátedras pelo regime departamental e a unificação da carreira de professor com a de pesquisador nas instituições federais de ensino superior, determinadas pelas leis n. 5.539/68 e n. 5.540/68. Estas e outras medidas fizeram parte do processo, ainda não concluído, de modernização das instituições de ensino superior segundo o modelo norte-americano. Houve, todavia, políticas inéditas, como a profissionalização universal e compulsória no ensino de $2^{\underline{0}}$ grau (Lei n. 5.92/71).

(vi) As afinidades eletivas de grupos que apoiaram o golpe e/ou, posteriormente, o prosseguimento da ditadura foram de fundamental importância para a definição de suas políticas, inclusive as educacionais. Em especial, as afinidades políticas com os grupos vencedores nas disputas em torno da LDB-61, isto é, os privatistas. Vale lembrar o papel destacado que a liderança da Igreja Católica desempenhou na legitimação dos interesses privatistas, não apenas de seus próprios, mas de todo o setor privado, 
que ainda não tinha força suficiente para dispensar o patrocínio que essa instituição religiosa propiciava (CUNHA; FERNANDES, 2012). Assim, a despeito da tendência estatista espontânea dos militares, políticas educacionais privatistas foram formuladas e implementadas como efeito de suas afinidades com o lado vencedor na luta pela LDB-61, inclusive e principalmente religiosos católicos, que foram estratégicos na preparação e efetivação do golpe de Estado de 1964, contra o "ateísmo marxista".

(vi) Não há dúvida de que a ditadura abriu caminho para uma inflexão das políticas educacionais, principalmente pelo fim do populismo. ${ }^{4} \mathrm{Com}$ efeito, o populismo deu o tom de várias delas no período imediatamente anterior. Cito, como exemplo, as "leis de equivalência" entre os ramos profissionais do ensino médio ao ramo secundário, em 1950 e 1953, bem como o decreto do presidente Goulart de duplicação das vagas nos vestibulares de 1964. A partir do golpe, os grupos de interesse de apoiadores diretos passaram a ser decisivos na formulação e implementação de políticas. Contudo, cumpre não esquecer que essa inflexão foi antecedida por outra, bem próxima, a impressa pela Lei de Diretrizes e Bases da Educação Nacional - LDB (Lei n. 4.024/61), a qual permaneceu em vigor. Ela só começou a ser alterada pelas leis n. 5.540/68 e n. 5.692/71. Em pelo menos um ponto ela foi decisiva para a implementação de políticas educacionais privatistas em todos os níveis do Estado: a determinação de que os Conselhos de Educação tivessem representantes do "magistério oficial e particular", que logo foi ressignificado para incluir, necessariamente, os empresários do ensino.

Posto isso, apresento, então, minha tese: a de que o legado da ditadura para a educação pública resultou de dois vetores: ${ }^{5}$ (i) a educação tratada em função da simbiose Estado-capital; e (ii) a educação tratada como instrumento de regeneração moral do indivíduo e da sociedade. Vejamos cada um deles.

\section{Simbiose Estado-capital}

A ditadura não inventou a dualidade setorial pública/privada na educação, tampouco a simbiose Estado-capital na economia. O que ela fez foi intensificar essa dualidade fundante da educação brasileira e combiná-la, de modo peculiar, com os níveis de ensino, o superior e o básico. ${ }^{6}$ A educação foi submetida à simbiose ${ }^{7}$ Estado-capital, em cada nível de um jeito próprio. Comecemos pelo nível superior.

A reforma do ensino superior realizada durante a ditadura propiciou condições institucionais para a efetiva criação da instituição universitária no Brasil, onde, 
até então, existiam somente faculdades isoladas ou ligadas por laços mais simbólicos do que propriamente administrativos e acadêmicos. Mas tudo isso só pôde acontecer no bojo de forte repressão policial-militar.

Embora defendida por professores e estudantes, desde princípios da década de 1960, a reforma universitária foi possibilitada justamente pela repressão político-ideológica. Os atos institucionais baixados pelos governos militares, seus decretos-leis e a Constituição de 1967 abriram caminho para a extinção do regime de cátedras e a modernização da organização administrativa e acadêmica nas instituições federais de ensino superior, segundo o princípio da eliminação da duplicação de meios para fins idênticos ou equivalentes.

Por um lado, uma aliança tácita entre docentes-pesquisadores experientes e militares desenvolvimentistas fez com que as agências estatais de fomento ampliassem em muito os recursos destinados à pós-graduação; novos prédios foram construídos e laboratórios foram equipados; a profissão docente foi institucionalizada mediante o regime de tempo integral e de dedicação exclusiva; as instituições públicas de ensino superior ampliaram expressivamente o número de estudantes nelas matriculados.

Conseguido o controle dessas instâncias do Estado, a expansão do ensino privado foi muito intensa após o golpe de 1964, processando-se à velocidade tão mais alta quanto mais elevada a taxa de lucratividade média em cada nível de ensino: maior na educação superior do que na básica.

As afinidades políticas entre os governos militares e os dirigentes de instituições privadas do ensino superior fizeram com que o CFE assumisse uma feição crescentemente privatista. Assim, no momento em que a reforma da educação superior proclamava sua preferência pela universidade como forma própria de organização, o CFE se empenhava em propiciar a aceleração do crescimento dos estabelecimentos privados, a grande maioria deles isolados, contrariando a lei recentemente promulgada. O Congresso Nacional, fechado pelo acirramento da ditadura, menos de um mês após a promulgação da Lei da Reforma Universitária, permaneceu à margem desse novo impulso atomizador acionado pelos grupos privatistas. Medidas de menor status jurídico do que as resoluções do CFE, mas de grande alcance para a acumulação de capital, foram sendo implementadas, de acordo com as demandas dos grupos interessados.

Aprovada a LDB-61 e desfechado o golpe de Estado, os empresários do ensino dispensaram a Igreja Católica para legitimar seus projetos de acumulação, os quais rapidamente se deslocaram para o nível superior. Enquanto centenas de colégios católicos fechavam suas portas, ${ }^{8}$ outros tantos, de caráter empresarial, eram criados em áreas urbanas e suburbanas não atingidas pelas redes públicas de ensino, que, 
no entanto, cresciam rapidamente. Elas eram impulsionadas pelas campanhas eleitorais para as instâncias do Poder Legislativo, que não foram abolidas pela ditadura, a despeito do estreitamento de sua competência.

Empurrada pela elevação dos requisitos educacionais para o emprego, espontâneos e induzidos, a busca de diplomas de cursos superiores, nas mais diversas especialidades, abriu um mercado imenso para os empresários da educação. De norte a sul, são conhecidos exemplos de escolas de nível médio de pequeno porte que passaram a abrigar cursos superiores noturnos, as quais, após alguns anos, transformaram-se em grandes universidades. O lugar da mais rápida acumulação de capital havia passado, então, do nível médio para o nível superior.

Essa rápida expansão do setor privado no nível superior foi, de certa forma, funcional para o crescimento mais moderado do setor público. Aliviado da pressão da demanda, que, nos anos de 1967 e 1968, reivindicava "mais vagas" e "mais verbas" para as universidades públicas, estas puderam se concentrar na construção e no equipamento de grandes campus, de implementar programas de pós-graduação e pesquisa, assim como enviar professores e estudantes para prosseguir seus estudos no exterior.

Mais do que nunca, a estrutura discriminatória do ensino superior ficou aparente: universidades públicas para os estudantes de mais elevado capital cultural, universidades e faculdades isoladas privadas para os outros. Em termos probabilísticos, essa divisão de capital cultural era determinada pela renda, embora não diretamente. Parte das instituições privadas, no todo ou em parte dos cursos oferecidos, se especializaram em captar a demanda de baixo capital cultural e alta renda.

O empresariado do ensino foi bastante favorecido pela legislação tributária. Além de cassar o mandato de numerosos parlamentares e aposentar compulsoriamente militares que não apoiavam o aprofundamento da intervenção castrense no campo político, o Ato Institucional n. 2 determinou as eleições indiretas para presidente da República e governadores dos estados, e extinguiu os partidos políticos existentes, impondo limitações para sua reorganização. Um mês após esse ato de força, o Congresso Nacional, já mutilado, foi convocado para aprovar emenda à Constituição de 1946, que reformulou profundamente o sistema tributário nacional. A isenção fiscal das escolas privadas foi ampliada. Além da isenção de impostos sobre os bens e os serviços, a emenda de 1965 estendeu a isenção à sua renda. A Constituição de 1967 e a emenda de 1969 mantiveram esse dispositivo, de modo que as escolas privadas continuaram a gozar de verdadeira imunidade fiscal, o que ampliou suas possibilidades de lucros.

Na educação básica, a demanda incidente sobre os estabelecimentos privados sofreu uma importante mudança. Desde os anos do "milagre econômico", a 
ampliação das camadas médias, pelo menos em número de pessoas de rendimentos médios, propiciou uma clientela ávida de escola privada, não só como símbolo de status prestigioso, mas, também, como alternativa para o ensino público que se deteriorava a cada ano, por força das políticas elaboradas e implementadas pelos empresários do ensino e seus prepostos, que ocupavam o Ministério da Educação, as secretarias estaduais e municipais, bem como os conselhos federal e estaduais de Educação. A experimentação curricular irresponsável e o rebaixamento dos salários dos professores constituíram o eixo dessas políticas. Para se ter uma ideia da velocidade da deterioração dos salários, os professores da rede estadual paulista recebiam, em média, 8,7 vezes o salário-mínimo horário, em 1967; em 1979, essa relação havia baixado para 5,7 vezes. E continuou caindo, apesar das greves pela reconstituição do valor dos salários, a partir da segunda metade da década de 1970, em todo o país (CUNHA, 1991).

Se o aumento da demanda de alunos que podiam pagar e a imunidade fiscal eram suficientes para as escolas privadas destinadas aos alunos de mais alta renda, aquelas destinadas aos alunos de renda mais baixa, na periferia das cidades, onde as redes públicas não chegavam, receberam incentivos financeiros especiais, dos quais o mais importante foi o salário-educação.

No ano do golpe de Estado, o Congresso Nacional regulamentou dispositivo da Constituição de 1946, que instituía tributo devido por todas as empresas, públicas e privadas, destinado ao financiamento do ensino primário. Cada uma delas deveria pagar uma quantia calculada à base de 1,4\%, depois elevado para 2,5\% da folha de salários pagos aos empregados de todos os níveis e tipos. Os vultosos recursos gerados pela Lei n. 4.440/64, que regulamentou esse dispositivo constitucional, seriam destinados à expansão das redes públicas de ensino de estados e municípios. No entanto, se os empresários desejassem uma opção privada, poderiam substituir o recolhimento desse tributo pela manutenção de escola primária para seus trabalhadores e filhos deles, possibilidade essa que foi sendo aberta, de modo que a quantia devida poderia ser transferida diretamente a quaisquer escolas privadas, na forma de bolsas de estudos a quaisquer alunos.

Em 1981, as bolsas e as indenizações de gastos propiciadas por recursos do salário-educação correspondiam a $70 \%$ das vagas das escolas privadas de $1^{\circ}$ grau do país. Como havia outras fontes de bolsas para o setor privado do ensino, estimou-se que o número total desse benefício igualasse o do número de matrículas (VELLOSO, 1987).

Em 21 de novembro de 1968 (menos de um mês antes da promulgação do Ato Institucional n. 5) foi promulgada a Lei n. 5.537, que criou o Fundo Nacional de Desenvolvimento da Educação (FNDE). Sua finalidade era reunir recursos financeiros governamentais de diversas fontes e canalizá-los para o financiamento de projetos 
de ensino, inclusive alimentação escolar e bolsas de estudo para alunos carentes na rede privada. Os projetos seriam apresentados pelo governo federal e pelos governos estaduais e municipais, bem como por estabelecimentos privados. As escolas dariam uma compensação pelo financiamento recebido, mediante a reserva de vagas para bolsas de estudo, bolsas de manutenção ou de estágio, distribuídas pelo próprio FNDE.

Em suma, fundos públicos, criados por decisão estatal para financiarem a expansão das redes públicas, acabaram sendo estratégicos para a manutenção e a expansão do setor privado.

Dois anos após a promulgação da reforma do ensino de $1^{\underline{0}}$ e $2^{\mathrm{o}}$ graus, foi baixado o Decreto n. 72.495, de 19 de julho de 1973, que estabeleceu normas para a concessão de amparo técnico e financeiro às entidades privadas de ensino, com recursos do FNDE. Entre seus objetivos estava o de suprir as deficiências das redes públicas, mediante o aproveitamento da capacidade ociosa das escolas privadas. O decreto previa financiamento para a ampliação e reforma de imóveis, além de equipamento correspondente. Esses empréstimos às escolas privadas não seriam reembolsados. Elas compensariam o governo concedendo gratuidade total ou parcial de seu ensino, no valor do custo real, a ser estabelecido na época do recebimento dos recursos.

O dispositivo mais acintosamente privatista desse decreto determinava que os governos estaduais, ao elaborarem seus planos de educação, evitassem o que se entendia como duplicação de esforços, levando em conta a existência de instituições privadas. Em suma, deveriam evitar a criação de escolas públicas nas localidades onde o atendimento das escolas privadas fosse suficiente para absorver a demanda efetiva ou contida. A solução era a de sempre: a concessão de bolsas de estudo a alunos carentes de meios materiais para frequentá-las.

Nos governos estaduais que resultaram das eleições de 1982, as primeiras diretas após o AI-2, a expansão do ensino público de $1^{\circ}$ e $2^{\underline{o}}$ graus foi priorizada, por razões de política prática ou programática.

Tudo somado, a educação básica passou a ser majoritariamente pública. Em 2013 , apenas $16,5 \%$ dos alunos frequentavam escolas privadas, ao passo que $83,5 \%$ o faziam em escolas públicas.

O prosseguimento do processo de transição para a democracia propiciou uma nova LDB, em 1996, que foi sancionada pelo presidente Fernando Henrique Cardoso, cujo ministro da Educação acompanhou e influenciou diretamente o projeto aprovado pelo Congresso. O texto da lei admitia a transferência de recursos públicos para instituições educacionais privadas, sem fins lucrativos, desde que 
fossem comunitárias, confessionais ou filantrópicas, segundo normas a serem definidas por lei.

A reconfiguração começou pelo nível de ensino mais elevado, como em todas as reformas anteriores. A grande novidade foi o aparecimento dos centros universitários, que receberam o privilégio da autonomia para criar, organizar e extinguir, em sua sede, cursos e programas de educação superior, o que era, até então, privilégio das universidades propriamente ditas.

A privatização do ensino superior foi acelerada no octênio FHC. O número de instituições privadas aumentou consideravelmente, em especial na categoria universidades e na dos centros universitários, o que resultou na ampliação do alunado abrangido pelo setor. Tal crescimento se fez com a complacência governamental diante da qualidade insuficiente do ensino ministrado nas instituições privadas.

A categoria centro universitário foi de grande proveito para as instituições privadas de ensino superior, pois, além do status mais elevado do que o de faculdades, institutos ou escolas, elas poderiam adaptar-se ao mercado mais rápida e facilmente, mediante a criação/desativação de cursos de graduação e da alteração do número de vagas, sem os ônus impostos pela LDB-96 às universidades, tais como a oferta de certo número de cursos de pós-graduação estrito senso e certa proporção do corpo docente com mestrado ou doutorado, além da exigência de que parte dele fosse contratada em regime de tempo integral. O status de universidade deixou de ser almejado pela maior parte das instituições privadas, pois, enquanto centros universitários, melhorariam sua relação benefício/custo. Assim, em 2012, apenas dez centros universitários eram públicos, ao passo que 139 eram privados. As universidades públicas continuaram em maioria: 108 contra 85 privadas.

Nova inflexão no desenvolvimento da simbiose Estado-capital ocorreu no Governo Lula, com o Programa Universidade para Todos (Prouni). ${ }^{9}$ O programa foi ao encontro da demanda de acesso ao ensino superior gratuito, não atendida pelas instituições públicas, e com a determinação do Plano Nacional de Educação (Lei n. 10.172, de 9 de janeiro de 2001) de aumentar a taxa de escolarização dos jovens de 18 a 24 anos, no ensino superior, de $12 \%$ para 30\%, até o final da década, mas de um modo tal que a participação do setor público fosse igual ou maior a $40 \%$ do alunado. Não haveria, contudo, transferência líquida de recursos ao setor privado de ensino, pela regulamentação do dispositivo constitucional que previa a renúncia fiscal. O fundamento era o mesmo que prevaleceu na educação básica, durante décadas: bolsas de estudo para os estudantes não atendidos pelas redes públicas frequentarem escolas privadas. Desta feita, ao invés de aporte de recursos, haveria uma espécie de contrapartida pela isenção fiscal, o que tampouco exigiria dispêndios das instituições privadas, já que sua capacidade ociosa era alta, da ordem de $50 \%$. 
O projeto de lei enviado à Câmara dos Deputados, em 2004, encontrou o empresariado do ensino fortemente representado e ativo na adaptação dos seus termos aos interesses imediatos do setor. Um turbulento processo político resultou na Lei n. 11.096, de 13 de janeiro de 2005.

Os beneficiados do Prouni seriam estudantes provenientes de famílias de baixa renda, negros, indígenas e pardos, deficientes físicos e professores das redes púbicas de ensino (neste caso, independentemente de situação financeira e racial). Para participarem do Programa, as instituições de ensino superior teriam de firmar documento de adesão, que estipularia as condições previstas para um prazo de dez anos, renovável indefinidamente. As instituições aderentes deveriam oferecer bolsas integrais e parciais, em proporções definidas pela lei, relativas ao conjunto de seus estudantes pagantes. ${ }^{10}$

A lei do Prouni reconheceu o status de instituições educacionais com fins lucrativos, que aparecia de modo implícito na LDB-96. Desde então, as instituições de ensino superior podem ter fins lucrativos, pagar os impostos e contribuições a que estão sujeitas as empresas de serviços e distribuir lucros abertamente aos seus proprietários ou acionistas. Elas podem ou não aderir ao Prouni, caso em que fazem jus à isenção fiscal e à compensação prevista na lei. No outro extremo do espectro institucional privado, as instituições filantrópicas são obrigadas a aderir ao Programa e têm de atender condições mais exigentes do que aquelas, em termos de proporção de alunos beneficiados e do montante de bolsas integrais. Vale dizer, para as instituições filantrópicas, a contrapartida da isenção fiscal é maior. Em consequência, desenvolveu-se um processo de migração de instituições - da condição de filantrópicas para a de fins lucrativos. Nessa migração, elas levam consigo o capital acumulado com base em financiamentos de agências governamentais a juros privilegiados. Em suma, trata-se de doação de capital do setor público para o setor privado.

A avaliação do Prouni, do ponto de vista do volume dos beneficiários, é dificultada pela parcialidade das informações prestadas. O número de bolsas concedidas é divulgado amplamente, mas não o dos estudantes efetivamente delas beneficiários. Há quem estime em $35 \%$ a proporção de bolsas não utilizadas do montante de 1.200.000 oferecidas no período 2005/2010.

Apesar do crescimento do número de estudantes das instituições públicas de ensino superior, o das instituições privadas foi ainda mais rápido, impulsionado inclusive pelo Prouni, de modo que não foi atingida a meta do Plano Nacional de Educação 2001/2011. Em 2013, ao invés da participação do setor público nesse nível de ensino ser de $40 \%$, como projetado, não passou de $27,2 \%$, menos da metade do início da ditadura (56,3\% em 1965). 


\section{Educação para a regeneração moral}

A ideia da regeneração do indivíduo é essencial para o cristianismo, desde o início. A regeneração, isto é, o "nascer de novo", apelo que o próprio Jesus teria feito aos discípulos, dependeria da graça divina, mas, principalmente, do esforço individual. Essa ideia foi incorporada pelo positivismo de Augusto Comte, que pretendeu substituí-lo pela Religião da Humanidade, de cuja Igreja ele foi o supremo sacerdote.

A função dirigente que Comte atribuiu aos industriais foi assumida, no Brasil, pelos militares, a partir das três últimas décadas do século XIX. Com efeito, o Positivismo desempenhou o papel de ideologia orientadora da luta dos militares, principalmente do Exército, pela conquista de uma função dirigente no Estado e na sociedade, a partir do fim da guerra da tríplice aliança. Forneceu, também, a base de entendimento da regeneração moral da sociedade imperial, cujos valores decadentes seriam substituídos por valores positivos, inculcados por uma ditadura republicana (SEPULVEDA, 2010). Mesmo quando perdeu a hegemonia nos meios militares, o pensamento comteano permaneceu difuso nele, inclusive a ideia da regeneração social. Assim, quando o movimento católico leigo passou a atuar no Exército, ele encontrou, ou melhor, reencontrou a antiga vertente, embora mais social do que individual. A unir católicos e positivistas existia a ideia de que a crise da sociedade residia no egoísmo da elite e do povo, nas palavras de Teixeira Mendes (1913). A regeneração da sociedade passava, então, para ambos os protagonistas do pensamento político conservador, por uma educação pautada pela busca do bem comum, mediante o altruísmo, para os positivistas; e a caridade, para os católicos.

No início da década de 1960, formou-se na Escola Superior de Guerra uma corrente de pensamento que defendia a inclusão dos valores morais e espirituais entre os Objetivos Nacionais Permanentes. O líder dessa corrente foi o general Moacir Araújo Lopes, que veio a ser um dos próceres da Educação Moral e Cívica, chegando a presidente da comissão correspondente do Ministério da Educação.

A ideia subjacente era a de que se impunha "enfrentar o desafio maior do século, em que as nossas mais caras tradições democráticas e cristãs se veem ameaçadas pelo materialismo marxista". Em consequência, a "infiltração comunista" foi responsabilizada pela "queda nos padrões de comportamento social", a qual deveria ser combatida pelo ensino da Moral e do Civismo. Essa ideia gerou outra, após o golpe de Estado: a de que o "saneamento moral da sociedade" constituiria uma condição indispensável para o desenvolvimento (ARRUDA, 1980, p. 158).

Enquanto isso, no campo religioso, o antigo papel da Igreja Católica de difusora de ideologias tendentes à manutenção da ordem foi enfraquecido pelo aggiornamento promovido pelo Concílio Vaticano II. Transferindo seu tradicional foco 
elitista para a "opção preferencial pelos pobres", baseada na Teologia da Libertação, a instituição incentivou o engajamento social dos quadros religiosos e leigos, nos anos de 1960, visando disputar com os comunistas ou, em aliança com eles, participar da direção política dos movimentos sociais.

A Educação Moral e Cívica recebeu do Movimento de Arregimentação Feminina particular atenção. Em 1965, no ano seguinte ao do golpe de Estado, a entidade enviou manifesto da delegação brasileira à II Conferência Interamericana, promovida pela Organização dos Estados Americanos, cujo primeiro ponto reivindicava a "obrigatoriedade da educação moral e cívica nas escolas, desde as primeiras classes, para o aprimoramento do regime democrático e repulsa às ideologias totalitárias"; e o último continha um apelo "a todas as entidades de classe, grupos voluntários e meios de comunicação, para que assumam uma responsabilidade e criem um clima em todas as Américas, a fim de desenvolver um programa de formação moral e cívica e de fé ideológica democrática, baseada nos direitos humanos" (OLIVEIRA, 1982, p. 19-20).

Logo em seguida ao AI-5, o general presidente Costa e Silva sofreu derrame e uma junta militar ocupou seu lugar e depôs o vice-presidente Pedro Aleixo. Em 12 de setembro de 1969, a junta baixou o Decreto-Lei n. 869, proposto por um grupo de trabalho da Associação dos Diplomados da Escola Superior de Guerra, visando a inserção obrigatória da disciplina Educação Moral e Cívica nos currículos de todos os níveis e modalidades de ensino do país, tanto no setor público quanto no setor privado.

Apoiando-se nas tradições nacionais, a Educação Moral e Cívica teria por finalidade: a) a defesa do princípio democrático, através da preservação do espírito religioso, da dignidade da pessoa humana e do amor à liberdade com responsabilidade, sob a inspiração de Deus; b) a preservação, o fortalecimento e a projeção dos valores espirituais e éticos da nacionalidade; c) o fortalecimento da unidade nacional e do sentimento de solidariedade humana; d) o culto à pátria, aos seus símbolos, tradições, instituições e grandes vultos de sua história; e) o aprimoramento do caráter, com apoio na moral, na dedicação à família e à comunidade; f) a compreensão dos direitos e deveres dos brasileiros e o conhecimento da organização sócio-político-econômica do país; g) o preparo do cidadão para o exercício das atividades cívicas, com fundamento na moral, no patriotismo e na ação construtiva visando ao bem comum; h) o culto da obediência à lei, da fidelidade ao trabalho e da integração na comunidade.

Essa disciplina seria ministrada em todos os níveis de ensino, inclusive na pós-graduação, sendo que no ensino superior ela se apresentaria na forma dos Estudos de Problemas Brasileiros. Os programas, para todos os níveis, seriam elaborados pelo Conselho Federal de Educação, com a colaboração da Comissão Nacional de 
Moral e Civismo (CNMC), com seis membros nomeados pelo presidente da República, "dentre pessoas dedicadas à causa" (CUNHA, 2010). A CNMC reunia, entre seus membros, zelosos generais, que se articulavam com a censura federal, e civis militantes de direita, além de sacerdotes católicos. A primeira composição da comissão foi a seguinte: general Moacyr de Araújo Lopes, presidente; almirante Ary dos Santos Rangel; padre Francisco Leme Lopes; e os professores Elyvaldo Chagas de Oliveira, Alvaro Moutinho Neiva, Hélio de Alcântara Avelar, Guido Ivan de Carvalho e Humberto Grande. ${ }^{11}$

Enquanto os setores da Igreja Católica comprometidos com os movimentos populares e orientados pelo Concílio Vaticano II eram reprimidos pela ditadura e seus aliados, não faltaram clérigos que colaboraram com os militares na luta contra o "comunismo ateu". Na área de educação, o mais importante deles foi Luciano Cabral Duarte, arcebispo de Aracajú.

Em 1964, o arcebispo Duarte era já o mais destacado intelectual da corrente integrista da Igreja Católica, que resistia às mudanças induzidas pelo Concílio Vaticano II e seus desdobramentos teológicos e pastorais. No CFE, o arcebispo Duarte substituiu o padre Helder Câmara como "representante" da Igreja Católica. Não foi, portanto, por coincidência que o Parecer n. 94/71, do CFE, normatizando a Educação Moral e Cívica, aprovado em 4 de fevereiro de 1971, tenha sido relatado justamente por Luciano Cabral Duarte.

Apesar do parecer do arcebispo-conselheiro proclamar que a Educação Moral e Cívica deveria ser aconfessional, isto é, não vinculada a nenhuma religião e a nenhuma igreja, a incorporação da doutrina tradicional do catolicismo não era sequer disfarçada. O parecer proclamava que a religião era a base da moral a ser ensinada. Para escapar do paradoxo, o arcebispo Duarte lançou mão do conceito de "religião natural", isto é, aquela que leva ao conhecimento de Deus pela luz da razão. É claro que não estava explícita que razão era essa. De todo modo, ficavam afastadas todas as religiões afro-brasileiras, apesar de efetivamente praticadas por dezenas de milhões de pessoas, relegadas pelos moralistas e civilistas à condição de resíduos de ignorância ou de curiosidades folclóricas.

Além das diretrizes gerais para a Educação Moral e Cívica, o parecer apresentava programas detalhados dessa disciplina para o ensino primário, o ensino médio e o ensino superior. No primário, o conteúdo do ensino deveria estar centrado na "comunidade", esta categoria mitológica pela qual a direita celebra a coesão social e condena os diferentes e os desviantes - mito do qual a esquerda tem sido, por vezes, prisioneira.

No ensino médio (antigos ginásio e colégio) o conteúdo da disciplina já era mais explicitamente político-ideológico: o trabalho como um direito do homem é 
um dever social (pelo qual cada um dá a contribuição de que é capaz para fazer funcionar o conjunto da sociedade, sendo a exploração apenas um caso lamentável e excepcional); as principais características do sistema do governo brasileiro (apresentado como democrático, posto a salvo dos "socialistas e dos comunistas" pela "revolução redentora"12); a defesa das instituições, da propriedade privada e das tradições cristãs (com a rejeição das ideias exóticas que os agentes da subversão internacional estariam tentando inocular em nosso "povo simples e ingênuo", para dividi-lo por lutas fratricidas); a responsabilidade do cidadão para com a segurança nacional, isto é, para com a segurança do Estado, aceitando o governo autoritário, inclusive dos militares, que deteriam o monopólio do patriotismo e a clarividência das aspirações do povo brasileiro e dos Objetivos Nacionais Permanentes (CUNHA, 2010).

Enquanto a Educação Moral e Cívica, no ensino de $1^{\circ}$ e $2^{\circ}$ graus, esteve impregnada de cristianismo e de pensamento conservador, no ensino superior a composição foi da doutrina da segurança nacional com a visão tecnocrática dos problemas do país, ao lado de uma sociologia ingênua. Na prática, a Educação Moral e Cívica foi lugar de emprego preferencial para religiosos e militares, estes principalmente nos cursos superiores. No entanto, alguns professores conseguiam, à custa de artifícios, contornar os programas oficiais e desenvolver com os alunos atividades pertinentes de resistência ideológica.

As vicissitudes da transição para a democracia levaram a Educação Moral e Cívica a uma longa agonia, ao contrário do fim do Estado Novo, quando ela foi extinta imediatamente após a deposição de Vargas.

A LDB-96 elevou o Ensino Religioso a uma posição que ele não havia tido até então: ele foi considerado "parte integrante da formação básica do cidadão". Poderes especiais foram atribuídos aos sistemas de ensino (das Unidades da Federação e dos municípios) para estabelecerem normas para a habilitação e a admissão dos professores dessa disciplina. Ademais, foi reconhecido o poder de entidades civis formadas pelas diferentes denominações religiosas. Cada sistema educacional deveria ouvi-las na formulação dos respectivos programas.

Esse lance foi completado com a assinatura da concordata Brasil-Santa Sé/Vaticano. Em prosseguimento a gestões iniciadas durante a visita do Papa Bento XVI ao Brasil, em maio de 2007, a concordata foi firmada em novembro de 2008, pelo ministro brasileiro das Relações Exteriores e pelo secretário de Estado do Vaticano. O documento foi homologado pelo Congresso Nacional e, em 11 de fevereiro de 2010, o presidente Lula assinou o Decreto n. 7.107, promulgando a concordata.

Tornou-se realidade o que jamais acontecera, nem mesmo durante o Império, quando o catolicismo era religião oficial, e parecia impossível desde que, em 1889, o regime republicano extinguira o padroado imperial: a direção mundial da Igreja 
Católica logrou que o Estado brasileiro firmasse com ela um tratado que lhe garante privilégios especiais, em termos políticos, fiscais, trabalhistas, educacionais e outros.

O artigo 11 da concordata diz que o Ensino Religioso católico e de outras confissões religiosas, de matrícula facultativa, constitui disciplina dos horários normais das escolas públicas de ensino fundamental. Esse artigo contraria, essencialmente, o artigo 33 do texto reformado da LDB-96, o qual determina que o conteúdo da disciplina Ensino Religioso seja estabelecido pelos sistemas de ensino (federal, estaduais e municipais), depois de ouvidas entidades civis constituídas pelas diversas confissões religiosas. Assim, pode não haver "ensino religioso católico", nem de confissão específica alguma. Se esse conteúdo for de caráter histórico, sociológico ou antropológico, como pretendem certas correntes de opinião, ou um extrato das doutrinas religiosas conveniadas, o resultado dependerá da composição política de tais entidades civis.

Contrariamente, verifica-se, após a reforma da LDB, a enfática retomada da antiga demanda da Igreja Católica no sentido da efetiva implantação do Ensino Religioso nos sistemas públicos de educação básica.

Contudo, a retomada católica não se faz sem dissenso interno à própria burocracia eclesiástica, a respeito da estratégia orientadora de suas relações com os demais segmentos religiosos, o que tem repercutido sobre a direção a adotar no Ensino Religioso nas escolas públicas: para uma corrente, ele deve ser confessional, para outra, inter/supraconfessional. Recentemente, essas disputas se intensificaram, havendo até mesmo partidários da primeira corrente acusando os da segunda de pretenderem transformar o Ensino Religioso numa espécie de Educação Moral e Cívica, alusão dotada de forte conotação pejorativa.

Pesquisa realizada por Daniela Patti do Amaral identificou 13 projetos de lei apresentados por deputados e senadores no período 1997/2006, que procuravam reintroduzir nas escolas a Educação Moral e Cívica ou introduzir disciplinas que contemplassem a ética e a cidadania, em busca do regate de valores supostamente perdidos pela sociedade (AMARAL, 2007).

Atualmente, há vários projetos de lei em tramitação no Congresso Nacional com o objetivo de reintroduzir a Educação Moral e Cívica no currículo da educação básica, sob diversos nomes. Eles têm o componente religioso explícito ou implícito no texto do projeto e/ou na justificativa. Todos têm em comum a ideia de que a ética que falta no povo brasileiro é a defendida pelas religiões, especialmente as da vertente cristã.

Em setembro de 2012, foi aprovado pelo Senado e enviado à Câmara dos Deputados projeto de lei do senador Sérgio de Souza (PMDB-PR) que modifica 
a LDB-96, inserindo no currículo do ensino fundamental a disciplina Cidadania, Moral e Ética, e, no ensino médio, a disciplina Ética Social e Política. Menos ostensivamente religioso do que outros projetos, o senador paranaense previu a inserção das disciplinas Filosofia e Sociologia no ensino médio, de modo que resultou um mix peculiar, no qual o pensamento crítico coroaria a ideologia. A justificativa do senador é esclarecedora de sua motivação:

\begin{abstract}
Estou convencido de que, dessa forma, estaremos oferecendo a nossa sociedade instrumentos para o fortalecimento da formação de um cidadão brasileiro melhor, por um lado, pela formação, ensinando conceitos que se fundamentam na obediência a normas, tabus, costumes ou mandamentos culturais, hierárquicos ou religiosos; por outro lado, pela formação ética, ensinando conceitos que se fundamentam no exame dos hábitos de viver e do modo adequado da conduta em comunidade, solidificando a formação do caráter; e finalmente para sedimentar o exercício de uma visão crítica dos fatos sociais e políticos que figuram, conjunturalmente, na pauta prioritária da opinião pública, oferecendo aos jovens os primeiros contatos com as noções de democracia, sem caráter ideológico, ensinando-o a construir seu pensamento político por sua própria consciência. (PLS n. 2/2012)
\end{abstract}

O projeto foi enviado à Câmara dos Deputados, onde estará sujeito às vicissitudes das eleições parlamentares de 2014. Dificilmente será votado neste ano, de modo que será arquivado por determinação regimental. A retomada de sua tramitação dependerá da nova composição do Congresso Nacional e da competição com projetos afins oriundos da própria Câmara dos Deputados.

\title{
Conclusão
}

Os dois vetores permanecem ativos e não há previsão de que percam sua força num futuro previsível.

A simbiose Estado-capital passa, no campo educacional, por mudanças que podem até mesmo aumentar sua força. Do lado do capital, processa-se a concentração em grandes conglomerados, inclusive com capital estrangeiro, mediante a compra de pequenas faculdades e até mesmo de centros universitários e universidades. Do lado do Estado, o potencial de avaliação institucional decresce na medida em que as instituições privadas de baixo nível são as que mais dispõem de vagas ociosas para aderirem ao Prouni e matricularem estudantes beneficiados pelo Fies. Patrocinando, então, a absorção de um contingente significativo de estudantes pelo segmento de mais baixo nível do setor privado, o Estado caiu numa fatal armadilha: não poderá exercer os poderes que criou de descredenciar instituições de ensino superior de baixo nível para não prejudicar os estudantes, a não ser que o poder venha a ser ocupado por forças políticas que descartem qualquer traço da herança populista, tão cara à esquerda quanto à direita. 
Em termos ideológicos, reforça-se, a cada dia, o mote que afirma: "tudo o que é público é ruim, tudo que é bom é privado". No campo educacional, esse mote é empregado de modo bastante seletivo: em plena força na educação básica, na qual $83,5 \%$ dos alunos frequentaram escolas públicas, em 2013, justamente os mais pobres; na educação superior, o mote não se aplica, porque apenas $27,2 \%$ dos estudantes frequentaram as consensualmente boas universidades e faculdades públicas, justamente os de mais elevada renda. Ou seja, a seletividade da educação brasileira aumenta, apesar do crescimento do setor público: educação básica pública para as crianças e jovens de mais baixa renda, educação superior pública e gratuita para os de mais alta renda. Até o momento, as políticas de ação afirmativa, que beneficiam alunos provenientes de escolas públicas, combinadamente com critérios raciais, não foram suficientes para alterar essa perversa inversão na arquitetura do sistema educacional.

O vetor da regeneração moral pela via da educação tende a crescer, a curto e médio prazo, devido ao aumento da instrumentalização religiosa da política, pelo menos enquanto persistirem o "presidencialismo de coalizão" e o oportunismo partidário diante de outra simbiose: a da política com a religião. Mas esse vetor pode vir a perder força ou mesmo ser redirecionado pelo crescimento dos movimentos laicos, principalmente a partir da defesa dos direitos sexuais e reprodutivos, bem como da afirmação da identidade afro-brasileira, hoje alvo prioritário de combate pelos evangélicos pentecostais em ascensão. E é justamente essa ascensão que bem pode vir a abrir caminho a uma laicidade de dissuasão como efeito colateral dos conflitos que tendem a aumentar entre as duas vertentes do cristianismo: a decadente católica e a emergente evangélica.

No cruzamento dos dois vetores, o da simbiose Estado-capital e o da regeneração moral, emerge um segmento até então informal e oscilante em seu status: a instituição comunitária de educação superior. Esse segmento está representado pela Associação Brasileira das Universidades Comunitárias, que congrega instituições de ensino superior de diferentes tipos: 1.106 associadas, das quais 70 são universidades, 91 são centros universitários e 945 são faculdades isoladas. Esse segmento surgiu antes mesmo da LDB-96, com uma autoimagem constituída de uma dupla negação: de um lado, dizia-se privada, mas sem fins lucrativos; de outro, dizia-se pública, mas não estatal (CUNHA, 1991). O segmento compreende as instituições confessionais de ensino superior, inclusive as prestigiosas pontifícias universidades católicas, que lhe dão a orientação político-ideológica, e as cristãs não católicas, com destaque para as instituições presbiterianas e metodistas.

As instituições comunitárias já tinham representação própria no Conselho Nacional de Educação desde o governo FHC, mas sua grande vitória foi a promulgação da Lei n. 12.881, de 12 de novembro de 2013, resultante de projeto apresentado em 
2010 pela deputada petista Maria do Rosário Nunes, alçada à ministra dos Direitos Humanos da presidenta Dilma Rousseff. A lei previu que o status de instituição comunitária será outorgado pelo Ministério da Educação, mediante o cumprimento de certas condições, principalmente em termos de gestão, para que a agraciada receba recursos públicos. O oferecimento de ensino superior gratuito é uma dessas condições, mas apenas na proporção dos recursos públicos recebidos especificamente para esse fim. Recursos adicionais serão recebidos para que cada instituição comunitária oferte serviços públicos alternativamente às entidades estatais, sob a forma de parcerias.

Nas disposições finais dessa lei, um artigo veda às instituições comunitárias de educação superior financiar campanhas político-partidárias ou eleitorais. Nenhuma palavra sobre campanhas de caráter religioso, inclusive as que incidam contra políticas públicas sobre direitos sexuais e reprodutivos, por exemplo.

A conclusão que podemos tirar do já exposto é a persistência dos vetores simbiose Estado-capital e regeneração moral para configurarem a educação brasileira, mesmo após três décadas de transição da ditadura para a democracia. Talvez até mesmo por causa disso, a retomada das práticas populistas e a mais livre representação dos grupos de interesse no Congresso Nacional tenham propiciado a persistência desses vetores. Sua mudança depende, com certeza, mais do que da propalada "vontade política" dos ocupantes dos cargos executivos nos três níveis da Federação. Depende, sobretudo, da mais difícil e sempre adiada mudança no campo político brasileiro: a da representação popular e sua mediação partidária.

\section{Notas}

1. Ver, a propósito, Reis Filho, Ridente e Motta (2014).

2. Para uma pesquisa sobre a construção ideológica do mundo civil a partir do mundo militar, na Academia Militar das Agulhas Negras, ver Castro (2004).

3. Com essa afirmação, corrijo expressões empregadas em meus trabalhos anteriores, nos quais a influência da conjuntura política foi mais direta.

4. O combate sistemático ao populismo foi mais expressivo no nível federal do que nos níveis estadual e no municipal do Estado.

5. O termo vetor é de largo emprego na Matemática, na Física e na Epidemiologia. Neste artigo, vetor é entendido como "elemento de orientação, condução ou direcionamento", conforme o Dicionário Unesp.

6. O emprego do termo educação básica para todo o período aqui considerado constitui uma anacronismo na nomenclatura, que, todavia, não prejudica a análise.

7. Simbiose é empregada, neste texto, com significado inspirado no Dicionário Unesp, a saber: "associação de dois ou mais organismos vivos que traz benefícios mútuos".

8. Para o fim dos colégios católicos pesou a decisão de várias ordens e congregações religiosas de optarem pelos pobres, em função da reorientação do Concílio Vaticano II, o que raramente fez com 
que os colégios fossem redirecionados das elites para as massas. Prioridades não escolares levaram padres e freiras para fora das instituições escolares.

9. Na linha do senso comum, o Ministério da Educação chamou de universidades todas as instituições de ensino superior.

10. Para uma análise detalhada dessas condições, consultar Carvalho (2006).

11. Veterano ideólogo da ditadura varguista, Humberto Grande escreveu sobre a pedagogia do Estado Novo, ainda durante sua vigência, e sobre a Educação Moral e Cívica, logo após o golpe de Estado de 1964. Para uma análise da atuação da CNMC, especialmente das convergências e divergências com o Conselho Federal de Educação, ver Lemos (2011).

12. A adjetivação do golpe de Estado como "revolução redentora", logo na primeira hora e depois, evidencia a presença do elemento religioso na sua simbologia. No Dicionário Unesp, o mistério da Redenção foi significado como "o resgate do homem por Jesus Cristo, através de sua morte."

\section{Referências}

AMARAL, D.P. Ética, moral e civismo: difícil consenso. Cadernos de Pesquisa, São Paulo, v. 37, n. 131, p. 351-369, maio/ago. 2007.

ARRUDA, A. ESG: história de sua doutrina. São Paulo: GRD; Brasília, DF: INL-MEC, 1980.

BOURDIEU, P. A economia das trocas simbólicas. São Paulo: Perspectiva, 1974.

CARVALHO, C.H.A. O Prouni no governo Lula e o jogo político em torno do acesso ao ensino superior. Educação E Sociedade, Campinas, v. 27, n. 96, p. 979-1000, out. 2006.

CASTRO, C. O espírito militar: um antropólogo na caserna. Rio de Janeiro: Zahar, 2004.

CUNHA, L.A. Educação, Estado e democracia no Brasil. São Paulo: Cortez, 1991.

CUNHA, L.A. Desenvolvimento desigual e combinado no ensino superior: Estado e mercado. Educação E Sociedade, Campinas, v.25, n. 88, p. 795-817, out. 2004.

CUNHA, L.A. O ensino profissional na irradiação do industrialismo. São Paulo: Unesp, 2005.

CUNHA, L. A. A universidade reformada: o golpe de 1964 e a modernização do ensino superior. São Paulo: Unesp, 2007a.

CUNHA, L.A. O desenvolvimento meandroso da educação brasileira entre o Estado e o mercado. Educação E Sociedade, Campinas, v. 28, n. 100, p. 809-829, out. 2007b.

CUNHA, L.A. Sintonia oscilante: religião, moral e civismo no Brasil - 1931/1997. Cadernos de Pesquisa, São Paulo, v. 37, n. 131, p. 285-302, maio/ago. 2007c.

CUNHA, L.A. Ambiguidade ideológica na Universidade: os estudos de problemas brasileiros. Revista do CFCH, Rio de Janeiro, v. 1, n. 1, p. 10-33, jun. 2010. 
CUNHA, L.A.; FERNANDES, V. Um acordo insólito: ensino religioso sem ônus para os poderes públicos na primeira LDB. Educação \& Pesquisa, São Paulo, v. 38, n. 4, p. 849-864, out./dez. 2012.

DICIONÁRIO UNESP do Português Contemporâneo. São Paulo: Unesp, 2004.

LEMOS, K.S.C. A normatização da Educação Moral e Cívica (1961-1993). 2011. Dissertação (Mestrado em Educação) - Faculdade de Educação, Universidade Federal do Rio de Janeiro, Rio de Janeiro.

LERNER, S.M. A pós-graduação em Estudo de Problemas Brasileiros na UERJ: uma reflexão sociológica sobre um projeto de socialização política no Brasil. 2013. Tese (Doutorado em Sociologia) - Instituto de Ciências Sociais, Universidade do Estado do Rio de Janeiro, Rio de Janeiro.

MENDES, R.T. O ensino primário oficial e a regeneração humana. Rio de Janeiro: Igreja Positivista do Brasil, 1913.

OLIVEIRA, M.A.F.B. Política e educação no Brasil: a implantação da obrigatoriedade da Educação Moral e Cívica no ensino brasileiro em 1969. 1982. Dissertação (Mestrado em Educação) - Faculdade de Educação, Universidade de São Paulo, São Paulo.

REIS FILHO, D.A.; RIDENTI, M.; MOTTA, R.P. A ditadura que mudou o Brasil: 50 anos do golpe de 1964. Rio de Janeiro: Zahar, 2014.

SEPULVEDA, J.A.M. O papel da Escola Superior de Guerra na projeção do campo militar sobre o campo educacional. 2010. Tese (Doutorado em Educação) - Faculdade de Educação, Universidade Federal do Rio de Janeiro, Rio de Janeiro.

SOUZA, M.I.S. Os empresários e a educação: o Ipes e a política educacional após 1964. Petrópolis: Vozes, 1981.

VELLOSO, J. Política educacional e recursos para o ensino: o salário-educação e a universidade federal. Cadernos de Pesquisa, São Paulo, n. 61, p. 3-29, maio 1987.

Recebido em 23 de abril de 2014.

Aprovado em 16 de maio de 2014 